\title{
Near-Surface Chemical Alteration of Nineteenth-Century Architectural Cast Stone
}

Edward P. Vicenzi ${ }^{1,2}$, Carol A. Grissom ${ }^{1}$, A. Elena Charola ${ }^{1}$, Emily Aloiz ${ }^{1}$, Melvin J. Wachowiak ${ }^{1}$, Jeffrey Davis ${ }^{2}$, and John J. Donovan ${ }^{3}$

${ }^{1}$ Smithsonian Institution, Museum Conservation Institute, Suitland, MD USA

2. NIST, Materials Measurement Science Division, Gaithersburg, MD USA

3. University of Oregon, CAMCOR, Eugene, OR USA

Cast stone is broadly defined as architectural concrete that mimics cut stone in appearance. Molded circular discs of cast stone depicting intricate floral patterns, termed medallions, serve as decorative elements for the Smithsonian Institution's Arts and Industries Building (AIB) in Washington, D.C. (Figs. 1,2). The AIB was opened in 1881 and represents the first building constructed for the dedicated purpose of housing US national collections. Owing to problems regarding the structural integrity of the roof, the building was closed to the public in 2004 a nd is undergoing restoration for an anticipated $2014 \mathrm{r}$ eopening. Construction scaffolding has enabled access to medallions, which show signs of degradation principally by loss of a smooth, fine-grained surface layer and concomitant exposure of a more porous inner layer to the elements. Sampled fragments have been cross-sectioned, ground, and polished into optical thin sections. Regions near the atmosphere-medallion interface were examined using X-ray spectroscopic imaging in the SEM to document and understand the effects of weathering and other surface altering processes toward possible remedial action.

Alteration is expected to be most readily developed in the outermost cement portion of the cast stone, because partly contiguous voids make the small-grain-sized cement (sub-micrometer) permeable with respect to fluid exchange. Accordingly, we have concentrated our examination in this surface region of the specimens. Using MultiVariate Statistical (MVS) methods [1, 2] to model our hyperspectral X-ray data reveals an $\sim 7 \mu \mathrm{m}$ thick surface layer enriched in fluorine above an $\sim 20 \mu \mathrm{m}$ thick S-rich layer, which in turn overlies a thick (many 100s of $\mu \mathrm{m}$ ) zone of mixed calcium sulfate and carbonate cement (Fig. 3). In order to extract elemental information from chemical phases in the cement we have used the MVS results as input for an image processing algorithm [3] that outputs binary phase masks and associated spectra. Figure 4A shows the disposition of the most F-rich and S-rich pixels in the near-surface region and the derived spectra from these binary masks respectively (Figs. 4B,C). Figures $4 \mathrm{~B}$ and $\mathrm{C}$ also list elemental ratios of the principal peaks in these spectra, and these are consistent with $\mathrm{CaF}_{2}$ in the surface layer and an "oxygen deficient gypsum" $\left(\mathrm{CaSO}_{4} 2 \mathrm{H}_{2} \mathrm{O}\right)$ in the layer immediately below.

Sulfur originating from atmospheric pollution coupled with rain water infiltration have produced an enriched sulfate zone in AIB medallion cement microns from the surface. The Ca:S:O ratio suggests bassanite $\left(\mathrm{CaSO}_{4} 0.5 \mathrm{H}_{2} \mathrm{O}\right)$ rather than gypsum $\left(\mathrm{CaSO}_{4} 2 \mathrm{H}_{2} \mathrm{O}\right)$ is present, which could represent the desiccated product of an original gypsum coating [4]. $\mathrm{CaF}_{2}$ at the surface is likely the result of an $\mathrm{HF}$ acid cleaning applied to the building sometime after the buildup of sulfate.

[1] PG Kotula et al, Microscopy \& Microanalysis 9 (2003), p1-17.

[2] MR Keenan, Surface \& Interface Analysis 41 (2009), p.79-87.

[3] P Camus, Thermo Fisher Scientific TN52049 (2008), 9 p.

[4] D Vaniman, et al, Lunar \& Planetary Science Conf. (2009), \#1654. 


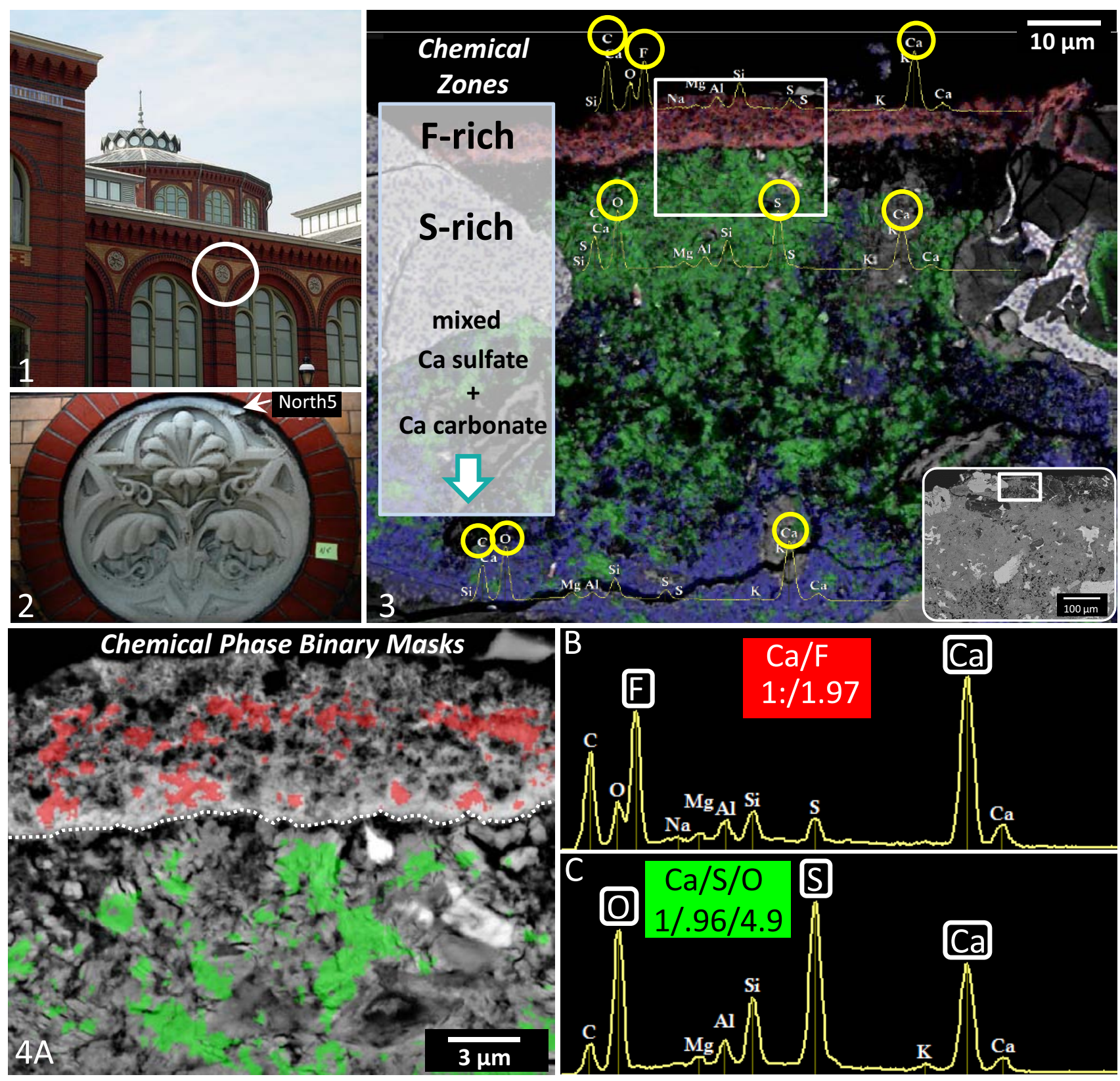

Figure 1. Photograph of the Smithsonian's Arts and Industries Building exterior showing circular architectural decorative elements (medallions) interspersed above arched windows. Figure 2. Medallion (diameter $=61$ $\mathrm{cm}$ ) with white arrow indicating sampling site. Figure 3. Chemical zonation in a polished cross section of cast stone as a function of depth from the surface. Red, green, and blue false color images represent multivariate statistical components of the X-ray data cube for the cement superimposed upon a BSE image with an overlay of their respective component spectra (inset: overview BSE image of examined region-white rectangle).

Figure 4. A) Detail of area highlighted in Fig 3. at the interface between the F-and S-rich zones. Chemical phase masks are superimposed on a BSE image representing the fluorine-rich (red) and sulfur-rich (green) zones whose interface is denoted by a dotted line. B) and C) Phase spectra derived from red and green pixels for F-rich (B) and S-rich (C) phases. Elemental ratios of major X-ray peaks in the spectra are expressed on an atom basis. 